\title{
RELATOS COMPARTILHADOS: EXPERIÊNCIAS DE CONVERSÃO AO PENTECOSTALISMO ENTRE BRASILEIROS E PORTUGUESES
}

Clara Mafra

Antropólogos e sociólogos da religião têm se deparado com importantes mudanças na dinâmica da conversão no meio evangélico nos últimos tempos, mudanças estas que vão tanto no sentido da intensificação do ritmo das conversões quanto no do crescimento das populações envolvidas. No Rio de Janeiro, por exemplo, segundo uma pesquisa de opinião realizada em 1994, 70\% dos membros das mais diferentes denominações não nasceram nem foram criados em um lar evangélico (Fernandes et alii 1998: 27). Desses 70\% convertidos em sua juventude ou maturidade, metade estava na sua igreja há menos de seis anos e $28 \%$ foram convertidos há menos de três. Além disso, tal intensificação no ritmo de conversão espelha-se diferentemente de acordo com as denominações, rearticulando o campo evangélico por inteiro e com implicações fora dele. Segundo a mesma pesquisa, se $66 \%$ dos Universais foram convertidos há menos de seis anos, o inverso ocorre na Assembléia de Deus, onde 56\% estavam na igreja há mais de sete anos (Fernandes et alii 1998:32). Da população total de evangélicos no Rio de Janeiro (12\% segundo o Censo de 1991), $61 \%$ vieram do catolicismo, $16 \%$ da umbanda e candomblé e $6 \%$ eram espíritas kardecistas (Fernandes et alii 1998:34) ${ }^{1}$.

Em Portugal podemos supor que processos similares têm se desenvolvido no meio pentecostal, ainda que com menor visibilidade e envolvendo populações menores: a maioria dos cerca de 200 mil membros que a Igreja Universal do Reino de Deus (IURD) afirma possuir, certamente, passou por processos recentes de conversão, levando-se em conta que a igreja se instalou no país em 1989 e só veio a ter presença nacional a partir de 1992. Pode-se sugerir, além disso, a partir do destaque que a Igreja Universal dá, na mídia portuguesa, à conversão de ex-bruxas, ex-adivinhos, ex-rezadeiras, ex-devotos de Fátima, que boa parte desses novos conversos são provenientes da maioria católica que convivia com crenças na agência do sobrenatural ${ }^{2}$. Contudo, essas mudanças na dinâmica da 
conversão têm sido pouco problematizadas e balizadas em relação às possíveis revisões conceituais que demandam.

Dentro e fora dos estudos de religião, a categoria "conversão" tem assumido significados diversos sem que, entretanto, os que estão disponíveis consigam descrever satisfatoriamente certas características importantes dos movimentos pentecostais contemporâneos, fortemente marcados por uma maior fragilidade, vulnerabilidade e pelo caráter pouco exclusivo e totalizante das novas adesões. Tradicionalmente, a idéia de conversão está associada a um processo de virada dramática na trajetória individual, em que "ego aceita um conjunto de crenças que questiona as estruturas cognitiva e de ação anterior ou em que ele retoma um conjunto de crenças e compromissos contra os quais um dia havia se rebelado" (Heirich 1977:654). Esta perspectiva informou boa parte dos estudos britânicos e norte-americanos na década de 70 sobre conversão religiosa (Heirich 1977), vários deles explorando questões de desvio e norma, continuidade/descontinuidade, conservadorismo/rebelião, pontos fortes de uma sociologia do desvio hegemônica no período. Isto não quer dizer que a questão seja apenas de preferência teórica do pesquisador, pois a perspectiva que vê na conversão uma virada dramática na orientação de vida do indivíduo responde também à própria configuração dos movimentos pentecostais da década de 70 (Heirich 1977; Novaes 1985; Fernandes et alii 1998), assim como está muito próxima de expectativas compartilhadas ainda hoje por alguns segmentos do movimento pentecostal — por exemplo, os pentecostais ligados à Maioria Moral nos Estados Unidos (Harding 1987). No passado ou no presente alguns grupos e movimentos religiosos estiveram atentos em incentivar processos de conversão marcados pelo dualismo, demandando do converso a adesão a uma visão que delimita fronteiras claras entre "o mundo" (externo) e o conjunto de crenças, usos e costumes compartilhados internamente.

Entretanto, uma possibilidade inversa, mais imprecisa e fragmentada da experiência de conversão, tem chamado a atenção dos pesquisadores nos processos de adesão aos movimentos religiosos contemporâneos. Ganha força a idéia de que os movimentos de passagem entre alguns cultos incluem um campo amplo de interlocução, um espaço de negociação entre os sistemas simbólicos em relação. Para dar conta da fluidez e do sincretismo presentes nesses processos de mudança, alguns autores têm, inclusive, optado pela rejeição à própria categoria de conversão, que tem funcionado como uma chave reificadora e simplificadora para a interpretação do processo. A crítica é especialmente dirigida ao foco sobre o indivíduo, como ressalta Birman: “[a conversão], por privile- 
giar a idéia de percurso individual, sobretudo por valorizar quase que exclusivamente a elaboração subjetiva e interior da crença, leva pouco em conta o contexto social e religioso que preside as mudanças ocorridas" (Birman 1996:90). Como contraponto, propõem-se a explorar com mais atenção os processos sociais, os contextos "de passagem" caracterizados pela "redefinição de fronteiras, de trocas simbólicas e de elaborações simbólicas, de inovações e de invenções em certa medida e que submete também à mudança os cultos envolvidos" (Birman 1996:90). Enfatizam-se, então, os dois lados do processo de reinterpretação e inovação simbólica, no qual o próprio missionário, proselitista ou propagador da "boa nova" acaba participando e incorporando conceitos, valores e significados da população ou indivíduo que pretende converter.

O ponto forte dessa perspectiva é a noção de que toda conversão envolve um exercício de tradução, cujo resultado é a transformação dos sistemas simbólicos em interação: estes não mais guardam o sentido original, do passado pré-conversão de um grupo social ou outro. De forma deliberada ou não, os movimentos proselitistas tendem a envolver uma negociação entre as categorias sociais de referência para garantir a inteligibilidade mútua e o desenvolvimento de um diálogo intersubjetivo através das fronteiras (Overing 1989; Meyer 1994).

A despeito das possibilidades abertas por essa segunda perspectiva, o problema é desconsiderar ou tomar como dado menor a participação do indivíduo nesses processos menos dualistas, mais sincréticos e indefinidos de conversão em função da valorização do contexto e dos sistemas simbólicos em relação. A riqueza estaria, a meu ver, em ir no sentido oposto da redução da participação do indivíduo no processo, uma vez que parece que muitos dos casos dessas dinâmicas minimalistas de conversão ocorrem em contextos marcados pela falta de referentes relativamente estabelecidos e duradouros sobre a reprodução social e, por isso mesmo, há uma maior disponibilidade para a criação e intervenção individual. Sobretudo, é complicado que nós pesquisadores, abandonemos o foco sobre o indivíduo justamente quando uma das fontes de sentido oferece um instrumento cultural que supõe um exercício individual de transformação do self, como é o caso da noção de conversão e testemunho propalada pelos pentecostais ${ }^{3}$.

Neste artigo, procuro indagar sobre o sentido atual da conversão entre os pentecostais, dando especial relevo a uma atualização específica, qual seja, a conversão minimalista. Minha abordagem apóia-se na hipótese de que o meio pentecostal tem aberto seu referencial simbólico para conviver com as nuanças e ambigüidades normalmente associadas 
às buscas de mudança de comportamento (e de adesão a novas ou ampliação das redes de significado compartilhadas) cuja responsabilidade repousa sobre o próprio indivíduo. Como fica evidente em outros experimentos sociais de apoio à transformação de trajetórias traumáticas alcoólicos, casais violentos, minorias oprimidas (Soares 1999) - a transformação individual não se faz de uma só vez, com a substituição de uma fonte de sentido por outra, mas exige um trabalho lento de reconstituição de referentes do passado e do presente da pessoa, que muitas vezes tem que lidar com categorias latentes de significado.

$\mathrm{O}$ argumento central deste artigo é que os pentecostais estão incentivando a experimentação sobre a mudança de sentido produzida pela conversão. Não é mais tanto o pastor ou o corpo de fiéis - a congregação - que ensina e guia de perto as opções abertas para o novo converso, mas ele mesmo vai adequando sua nova postura até, como dizem, se "sentir bem". Assim, o campo de negociação de significados, sobre o que deve ser recusado e o que deve ser aceito, o que tem valor de persuasão e o que deve ser combatido porque se revela ilusório, tende a responder a um diálogo entre a trajetória pessoal e o imaginário cosmológico pentecostal. A contraparte é a formação de coletivos mais plurais no interior dessas igrejas, tanto no que diz respeito a referentes culturais anteriores, como a estilos de vida a serem conquistados a partir da conversão.

Tal interpretação exige uma escuta atenta dos relatos individuais para então sugerir as recorrências e similaridades entre os relatos. O artigo está dividido em duas partes: uma primeira onde acompanho três relatos de conversão, detendo-me sobre esses casos justamente para compreender os meandros da experiência vivida e as categorias disponíveis para narrá-la. Na segunda parte, desloco o olhar de modo a apreender a estrutura significativa que articula a dinâmica da conversão.

Vale lembrar que esses três casos foram selecionados dentre os 45 que colhi ao longo de minha pesquisa de campo (trinta no Rio de Janeiro e quinze em Lisboa, Coimbra e Porto, em Portugal $)^{4}$ porque eles são especialmente significativos no que se refere ao leque de possibilidades disponíveis no campo pentecostal. Esses casos apresentam, ao mesmo tempo, uma enorme riqueza em termos singulares — quanto à trajetória individual, ao drama existencial vivido e à configuração social em que emergem - e acabam, no conjunto, sendo especialmente esclarecedores da qualidade e da diversidade da conversão pentecostal em sua formulação minimalista. 


\section{Deslocamento no foco socializador I: da conservação ao risco}

Conheci Maria de Fátima ${ }^{5}$ por intermédio de Cristina, uma pesquisadora portuguesa. Ela trabalhava na casa dos Vieira, pais de Cristina, já há longos anos. Nos últimos sete, da condição de empregada da matriarca, Maria de Fátima passara a circular por entre as casas dos irmãos, fazendo uma faxina aqui, cuidando das crianças ali, quebrando alguns galhos em toda parte. Interessei-me por saber como ela havia chegado à Igreja Universal do Reino de Deus, criando uma pequena lacuna no ambiente majoritariamente católico da tradicional família lisboeta dos seus patrões.

Maria de Fátima tem uma alta capacidade de observação e enorme respeito pela opinião de seus senhores, o que provavelmente a ajudou a tecer uma interpretação um tanto desencantada de sua conversão. Segundo conta, certo dia ela começou a sentir fortes dores, tremedeiras e uma imobilidade generalizada nas pernas. Quando tentava andar, explodia uma dor lancinante. Os médicos não chegaram a um diagnóstico definitivo sobre a origem da dor e da imobilidade, oscilando entre um problema de fundo nervoso e outro de natureza física na coluna cervical. Entre as idas e vindas aos médicos, chegou-se à indicação da realização de uma delicada cirurgia na coluna, que não excluiria a possibilidade de ela ficar paraplégica. Foi então que Maria de Fátima, que já escutava alguns programas da IURD no rádio, teve a coragem de visitar a igreja em companhia da mãe. É pelo que essa igreja fez naquele período que ela reconhece o valor da instituição.

Para Maria de Fátima sua cura é um mistério. O que ela sabe é que a freqüência aos cultos a ajudava. Na sua terceira visita, em uma noite da Corrente de Libertação, passou a reunião toda chorando, o que a fez sentir-se mais leve, mais livre, confortada. Entre a experiência de "libertação" vivida por Maria de Fátima — que não teria passado por nenhum momento de arrebatamento mais intenso que uma noite de choro convulsivo - e sua narrativa há um fosso de sentido e um vazio de palavras sobre o qual quero estabelecer algumas pontes.

A emergência das dores nas pernas está diretamente ligada a uma crise no relacionamento com outra empregada da família. O vínculo entre as duas foi se deteriorando paulatinamente, à medida que a amiga criticava e comentava de forma depreciativa as escolhas, ações e atitudes de Maria de Fátima junto à patroa. Articulou-se ali uma relação de forte animosidade reconhecida por Maria de Fátima e os demais membros da casa como de inveja. 
Inveja é um termo de acusação recorrente em contextos sociais baseados em uma forte noção de igualdade. A acusação pode ativar diferentes recursos sociais para inibir saliências individuais e o perigo de ultrapassar os limites do conhecido e do sabido, ajudando a conservar o status quo mantenedor da percepção de igualdade entre os iguais (Bailey 1971). Etnografias entre camponeses do Alto Minho (a região de onde Maria de Fátima veio) (Pina-Cabral 1989) e de comunidades pesqueiras também ao norte de Portugal (Cole 1994), dão destaque à dinâmica da inveja na estruturação da sociabilidade. Foi provavelmente uma atualização dessa elaboração cultural que Maria de Fátima encontrou em Lisboa, na rotina de seu dia-a-dia de empregada doméstica.

Se a inveja é um termo recorrente na cultura portuguesa, e se Maria de Fátima compartilhava esse universo simbólico desde a sua socialização à maturidade, por que justamente uma disputa perfeitamente previsível de inveja, com uma colega de trabalho, a conduziu a uma situação de forte tensão nervosa com sérias repercussões físicas?

Para se compreender em relação a que a ruptura se deu, é importante que se distinga como as conexões de sentido normalmente se estabeleciam antes do advento da crise corporal. Ocorre que Maria de Fátima vinha alimentando uma relação ambígua com respeito à dinâmica da inveja ao longo de sua trajetória de vida. Filha única de uma senhora humilde, abandonada pelo marido (que lá pelos anos 50 migrou para o Brasil) e devotada ao trabalho, ela viu sua possibilidade de continuar os estudos negada aos 12 anos porque sua mãe considerou adequado um futuro como costureira. Ela soube, anos depois, que a mãe a retirou da escola como uma medida educativa diante de uma filha que parecia confundir o seu lugar com o dos senhores com quem brincava na Quinta. Mais tarde, quando se tornou operária, Maria de Fátima descobriu que poderia aderir a dinâmicas de ascensão sem que o custo fosse maior que o estímulo. Por duas vezes, em diferentes empregos, conquistou posições superiores, de supervisão na linha de montagem, indo no sentido inverso à pressão de amigas e colegas que viam no aceite do cargo superior uma traição. Substituiu assim o perigo da inimizade e das acusações de suborno pela noção de valorização da própria capacidade: “Você só foi escolhida porque tem capacidade, e se foi escolhida, tem que ir em frente. Não pode ir na conversa das colegas" (entrevista com Maria de Fátima, 8/11/1997).

Na narrativa de Maria de Fátima, a inveja aparece recorrentemente como o tensor principal. De forma um tanto sub-reptícia, ela relaciona os mais diversos infortúnios passados a essa dinâmica - seja nos fracassos amorosos, nas dificuldades de relacionamento com colegas no trabalho, 
na perspectiva educacional negada. O caso da incompatibilidade de relacionamento entre ela e a colega de trabalho na casa dos Vieira aparece como mais um evento que se soma a uma trajetória de vida, confirmando a imersão de si e de suas relações na dinâmica da inveja. Foi justamente nesse período de saturação que Maria de Fátima procurou a IURD, o que "miraculosamente" reverteu a sensação de autodepreciação. Como podemos interpretar tal transformação?

Na análise tradicional do processo de conversão, parte-se do princípio de que o que aciona a dinâmica de conversão é alguma transformação interna - ainda que essa transformação venha como mero reflexo ou mimetismo diante da adesão a um novo grupo e ideologia — , afetando os fundamentos da ação, pensamento e percepção. Mas não vemos Maria de Fátima relatar qualquer mudança mais profunda em relação aos valores desposados ou aos grupos de referência. A participação dela na igreja não chegou a significar uma mudança na sociabilidade.

Para quem ouve a narrativa de Maria de Fátima, sua vida parece arranjar-se como uma linha que se estende continuamente, com altos e baixos, sem no entanto sofrer rupturas. Escutar sua história envolve um demorar-se nos pequenos segredos da vida, nos meandros das decisões e hesitações do cotidiano. A densidade da narrativa chega ao ouvinte através de um certo vagar, em um alongamento da linha do tempo tencionada por uma discreta progressão.

Os rituais da Igreja Universal contrastam com tempos longos como esse. Nos seus transes (de libertação, de glossolalia, dos choros convulsivos), no estilo emotivo das prédicas, no apregoamento dos milagres de fé, exploram-se ritmos intensos que podem ser repentinamente cortados, seguidos por silêncio para reverência ao sagrado. Esse jogo entre tempos fortes e fracos tem valor catártico. Com a ida à igreja, Maria de Fátima pôde contrastar sensível e esteticamente diferentes experiências de ritmo e duração. Com o contraste foi ganho, assim, gratuita, instantânea e fortuitamente, um entendimento, mas entendimento misterioso porque não poderia ser suficientemente compartilhado.

Minha hipótese é que houve uma transformação no jogo entre sistemas de significado em competição no seu meio, mais especificamente, Maria de Fátima deu um salto no que tange ao grau de liberdade com que acessa os diferentes referenciais ao seu alcance. Uma releitura da narrativa pode ilustrar o ponto: inicialmente, o foco de referência de memória de Maria de Fátima encontrava-se articulado ambiguamente entre a expectativa de ser solidariamente igual aos outros, com a valorização de modéstia e humildade no comportamento - valores tradicio- 
nais entre as mulheres das classes populares portuguesas - e o desejo mal formulado do gozo de sua capacidade e curiosidade pessoais. Depois da conversão, sua narrativa deslocou-se para uma formulação bem referendada sobre a sua capacidade de trabalho e de relacionamento humano, ambas positivamente qualificadas. Tais qualidades ligam-se à vida de Maria de Fátima porque ela as reconhece no seu próprio comportamento e escolhas pessoais ao longo de sua trajetória de vida, e que portanto, tanto quanto o habitus da inveja, da fofoca e da picuinha, estavam à disposição em suas lembranças. Entretanto, se essa auto-referência estava disponível muito antes da conversão, foi apenas através da conversão - esse instrumento cultural que a igreja ofereceu —, que Maria de Fátima teve acesso ao arcabouço de possibilidades sociais mais amplas, invertendo uma perspectiva depreciativa na seleção de significados. Note-se que a questão não é de ela ter substituído um padrão seletivo por outro, pois não houve aqui a substituição da sociabilidade regida por noções de inveja e igualitarismo por outro modelo coletivo. Houve antes a ampliação do espectro de elementos considerados na elaboração auto-reflexiva, para além daquilo que estava normatizado no grupo de referência.

A experiência de um momento de intensificação das emoções, como foi o choro convulsivo de Maria, é importante para esse exercício de relativização e desprendimento do indivíduo diante dos modelos de classe, status e sensibilidade consagrados e a seu dispor no contexto em que se encontra. No caso de Maria, tal instante promoveu uma nova atitude menos pautada pela tradição, diante de sua própria ação e intervenção no mundo, e mais moderna no sentido de assumir melhor os riscos do possível, as indeterminações da experiência, os frutos do acaso. Ela não se despojou do passado desligando-se dele de uma vez por todas, mas passou a relacionar-se com ele destradicionalizadamente ${ }^{6}$.

É importante que acentuemos a especificidade da presente interpretação pois não se trata apenas de a conversão permitir a elaboração de uma terceira possibilidade cultural a partir do encontro de dois sistemas de significados que estavam em relação, mas sim que Maria de Fátima pôde, a partir de então, perceber menos reificadamente sua cultura. Ou seja, a conversão pentecostal permitiu um outro modo de relacionamento do indivíduo com a tradição, à medida que ele passou a lidar com a perspectiva de movimentos mais amplos, aproveitando melhor as possibilidades dadas no presente, mas antes tidas como inalcançáveis. Contrariamente à ênfase das interpretações mais culturais, ressalto aqui que a questão central não é tanto o ganho de um novo referente cultural, mas 
de uma mudança no modo como o indivíduo se relaciona com a pluralidade de referentes culturais disponíveis, antes não percebida enquanto tal $^{7}$. O acompanhamento do segundo relato dará mais subsídios para se entender a abrangência e a complexidade das implicações desta interpretação da conversão.

\section{Deslocamento no foco socializador II: do risco à conservação}

No caso anterior de conversão, acompanhamos uma mudança individual experimentada quase solitariamente: apenas em um ou outro culto a mãe católica de Maria de Fátima acompanhou, a contragosto, a filha. De forma geral, a linguagem da conversão pentecostal não é um recurso cultural disponível no cotidiano português e, inclusive, para a população, há uma certa invisibilidade social dos (neo)pentecostais em diversos meios, sendo comum uma recusa das pessoas a se deixarem identificar por essa(s) religião(ões). O contraste com o Brasil, em especial com o Rio de Janeiro, é evidente, pois aqui os pentecostais têm uma presença numérica mais significativa ${ }^{8}$ e uma visibilidade social construída principalmente nos últimos dez anos. Um contexto como este último favorece a criação de redes sociais e linguagens religiosas e culturais, quer compartilhadas, quer disputadas, mas, de forma geral, apresentando inúmeras inter-relações, quando não evidentes sincretismos (Sanchis 1994; Birman 1996; Boyer 1996).

A história de Everaldo é um exemplo do forte movimento sincrético que vem ocorrendo entre religiões afro-brasileiras e pentecostais nos últimos anos. Filho de filha-de-santo, ele foi criado tocando tambor nos terreiros da Zona Sul do Rio de Janeiro. Aos 36 anos de idade, converteu-se e entrou para a Igreja Universal do Reino de Deus onde em pouco tempo foi promovido a obreiro, daí para a liderança de evangelização. Seu carisma e noções básicas de explicação da relação com o sobrenatural foram relativamente preservados nessa passagem, confirmando mais uma vez a continuidade entre as duas religiosidades. Outras descontinuidades significativas entretanto ocorreram, e é especialmente nelas que irei me deter, já que quero compreender os motivos de sua conversão.

As pessoas que conheceram Everaldo antes da conversão afirmam que ele viveu uma dessas transformações radicais, com rupturas claras na referência de masculinidade e no circuito de sociabilidade. O papel da esposa para produzir essas mudanças foi crucial. Como conta Everaldo: "O que me levou a me converter a Jesus foi o fato de eu ter passado 
uma fase com a minha esposa, de que ela já tinha deixado de conversar comigo, já estava até com minha roupa arrumada para eu ir embora" (entrevista com Everaldo, 5/5/1996).

Concentrando-me na narrativa de Everaldo, posso reconstruir sua história nos seguintes termos: até chegar a essa situação crítica próxima à expulsão de casa já havia transcorrido um longo tempo de disputas do casal. A esposa havia se convertido durante o casamento, quando a relação do casal estava desgastada. Everaldo conta que só tomou consciência daquela conversão quando percebeu uma mudança de postura na esposa, que passou a recusar as brigas e as discussões em função de uma atitude ponderada e segura. A típica precipitação e explosão emotiva foi substituída por um comportamento mais equilibrado. Mas se a mudança da esposa chamou a atenção de Everaldo e chegou a incomodá-lo, não foi suficiente para que ele transformasse o seu comportamento - a resposta que a esposa desejava. Ao contrário, ele continuava a sair com os amigos e a fazer novas conquistas entre as mulheres. A coincidência da rota do ônibus da mulher que, com um novo emprego, passou a circular justamente na porta do botequim que Everaldo freqüentava, ajudou ainda mais a agravar a crise do casal: foi aí que a mulher passou da desconfiança ao testemunho da infidelidade do marido.

Neste caso, Everaldo descreve como a esposa instituiu um modo de negociação diferente nas disputas do casal, pois ela passou a estabelecer um maior intervalo entre o estímulo e a resposta, mudando assim o ritmo e a dinâmica das brigas. Não havia mais tanto movimento, tanta ação e reação, típicos dos círculos viciosos das brigas de casal (Gregori 1993). Havia mais silêncios, não respostas, demoras. Essa transformação incomodava Everaldo, apresentando-lhe a suspeita de que algo ocorria fora de seu poder de influência. Foi para sanar as inúmeras dúvidas que surgiam sobre sua mulher que Everaldo foi pela primeira vez à Igreja Universal do Reino de Deus. Esse primeiro contato foi de empatia e maravilhamento: o pastor parecia falar diretamente com Everaldo, fazendo uma descrição adequada do seu comportamento, dúvidas e infortúnios, justificando o mal pela atuação real do demônio.

Ao contrário de Maria de Fátima, Everaldo relaciona sua mudança de comportamento na conversão com uma transformação ética: substituiu seu comportamento boêmio e descompromissado pela adesão maior aos papéis de pai e marido, duas funções sociais que demandam responsabilidade diante dos outros. Segundo conta, houve uma mudança inclusive de caráter: da postura de gozo diante da vida, passou a outra mais ponderada e produtiva, abandonando uma conduta regida pelo egoísmo 
e interesse próprio por uma de responsabilidade. A conversão, relatada nesses termos, assume contornos de descontinuidade e dualismo clássico: de um lado se alinham as perversões humanas e de outro as suas conquistas; de um lado o sofrimento, de outro a felicidade; de um lado o caos e a falta de bom senso, de outro a ordem e o bom senso ${ }^{9}$.

Da perspectiva de Everaldo, o salto ético está diretamente associado ao reconhecimento de "Jesus nele". Faz referência aqui ao apóstolo Paulo quando afirma "Já não sou eu mais quem vivo, mas Jesus Cristo que vive em mim". Foi através do "poder e autoridade de Jesus" que Everaldo conseguiu organizar sua vida segundo uma nova escala de valores, absolutamente contrastante com o comportamento anterior. Como podemos traduzir esse momento de virada em uma linguagem menos auto-referida?

Já descrevi a importância da esposa de Everaldo em sua conversão. Ela praticamente o levou até a porta de entrada da igreja, pressionandoo a uma decisão, sem obrigá-lo diretamente. Um dos preceitos mais generalizados entre os evangélicos é a entrega deliberada da responsabilidade dessa decisão ao indivíduo, entendendo-se que o limiar da passagem entre uma opção de vida e outra deve ocorrer segundo o livre-arbítrio da pessoa. Isto é um imperativo ético estruturante do meio evangélico, repetindo-se independentemente do bairro, cidade, região ou país ${ }^{10}$.

Entretanto, ao se contextualizar a narrativa de conversão de Everaldo no conjunto de sua história de vida fica evidente que, à semelhança do caso de Maria de Fátima, a virada da conversão se deu diante de uma profunda insatisfação de Everaldo consigo próprio. Indignava-se principalmente com o fato de estar dando continuidade ao comportamento habitual do pai que o magoara na infância e infernizara a vida de sua mãe. As poucas lembranças que guardava da figura paterna estavam relacionadas com um sentimento de ausência e inúmeros casos amorosos fora de casa. "O negócio dele era mulher e botequim", contou Everaldo em um tom seco.

O distanciamento da esposa diante de seu comportamento sedutor abriu espaço para a dúvida sobre seu habitus - habitus herdado e também esperado e compartilhado pelos amigos, a turma do pagode, os amigos da escola de samba. A pressão e a perseverança da esposa foram fundamentais para que essa dúvida se instalasse e fizesse efeito, permitindo que Everaldo desse uma volta reflexiva sobre si mesmo, retornando àquela primeira insatisfação da infância diante desse padrão de masculinidade ${ }^{11}$. Quando Everaldo foi ao culto assistir à primeira reunião, sua disponibilidade para uma interpretação negativa dos seus atos e pensamentos usuais estava dada. A linguagem religiosa simplesmente preencheu uma 
disposição pessoal em curso, moldando-a segundo a dicotomia que vimos anteriormente.

Seguindo uma tendência crescente no meio pentecostal atual, o dualismo na reinterpretação da trajetória de vida pós-conversão de Everaldo não implicou uma ressocialização completa e negação das qualidades pessoais já conhecidas: o bom papo, a inteligência, a prontidão na resposta, o conhecimento do demônio. Isto nos remete ao aspecto mais geral do fenômeno: da maior flexibilidade dos movimentos pentecostais nas últimas décadas, incorporando, cada vez com maior facilidade, as referências e diferenças pessoais como recursos internos. As estratégias homogeneizadoras de usos e costumes, eixo de atuação de denominações do pentecostalismo histórico, como a Assembléia de Deus e Deus é Amor, têm sido substituídas pela liberalização dos costumes e maior ousadia proselitista. Essa estratégia característica da Igreja Universal permitiu a Everaldo passar rapidamente de membro comum à função de obreiro, para na seqüência, em menos de um ano, disputar postos de liderança entre os obreiros. O aproveitamento do capital cultural acumulado de Everaldo ilustra a existência de continuidades entre uma religiosidade afro-brasileira e outra pentecostal ${ }^{12}$. No plano intra-subjetivo, a conversão inaugurou uma ruptura na autopercepção de Everaldo que não inibiu a expressão do que havia acumulado anteriormente. O novo Everaldo não negou certas facetas do velho: o que ficou?

A meu ver, assim como no caso de Maria de Fátima, Everaldo sofreu uma transformação no grau de liberdade com que articula os referentes culturais disponíveis, ainda que neste caso, ao contrário do anterior, o apoio da igreja na sustentação do modelo que se quer mimetizar tenha tido um peso considerável. Ou seja, mesmo que Everaldo tenha encontrado um filtro mais seletivo para suas ações e comportamentos - pois se sente comprometido com um modelo de masculinidade mais solidário e cordato que outros disponíveis - , ele não recusou de uma hora para outra toda sua trajetória anterior. Inclusive, é a possibilidade de continuidade com o passado que lhe dá confiança em sua expressividade, no seu dom para o exercício ativo de uma vida pública, seu reconhecimento enquanto compositor. Na nova fase, ele parece administrar as continuidades e descontinuidades da sua história pessoal segundo uma nova economia temporal, menos amarrada à possibilidade do momento, mais comprometida com projeções de futuro.

O ponto a ser salientado é que mudou o modo como Everaldo enfoca suas lembranças, explorando-as, depois da conversão, prioritariamente, segundo uma perspectiva progressiva. Com a noção de eventos que 
se somam para formar uma nova possibilidade positiva no futuro, o dinamismo do vivido desloca-se do ritmo vibrante do "estar em comunhão" das festas, que faziam parte do cotidiano de Everaldo, para a busca do desequilíbrio positivo entre o que foi e o que virá, articulando o conjunto da trajetória em uma linha em progressão.

Note-se que nesta análise da conversão minimalista, a apropriação da religiosidade pentecostal pode-se realizar muito plasticamente: enquanto na trajetória de Maria de Fátima fez diferença o ritmo vibrante do culto e do transe pentecostal, para Everaldo a informação relevante é a da continuidade, cujo referencial forte está no antagonismo presente tanto na religiosidade afro-brasileira como na neopentecostal. Ao contrário da dinâmica de conversão maximalista, no caso da conversão minimalista há uma menor disciplinarização quanto à receptividade da mensagem religiosa, garantindo-se assim que conversos de uma mesma denominação se apropriem das mais variadas formas de um mesmo referencial religioso, articulando de um modo não previsível os diferentes níveis de continuidade e descontinuidade.

No caso de Everaldo, a igreja pentecostal, além de ter oferecido o recurso cultural fundamental da mudança - a conversão - colocou-se como o sistema institucional mais imediato, acessível e disponível para o desenvolvimento da nova trajetória de vida. Em outras palavras, a IURD afirmou-se como a instituição de referência que, enquanto aspecto básico de toda instituição, se tornou doadora e mantenedora de continuidades - sendo esta a condição básica para a articulação do tempo em progressão. Tornou-se, portanto, um recurso cultural sedutor em face de uma história de vida com poucos referenciais de estabilidade.

A análise dos dois relatos anteriores explica a mudança de postura de fiéis a partir da conversão como um salto no modo de relacionamento do indivíduo com as alternativas plurais de comportamento, valores e hábitos presentes no seu contexto e não apenas como uma passagem de um sistema significativo para outro. Daí uma certa transitividade entre o que era antes e o que veio a ser depois da conversão, uma certa ambigüidade e continuidade entre referentes sociais, religiosos e pessoais atravessando a fronteira da conversão.

A questão que proponho em seguida é se essa maior liberdade do indivíduo converso para lidar com os referentes culturais disponíveis resulta da centralidade do indivíduo na tomada de decisão. Ou seja, os novos conversos relacionam-se menos reificadamente com a rede de significados disponíveis localmente porque passaram a levar mais em conta a sua própria subjetividade? A conversão estaria, então, servindo como 
um instrumento cultural que promove um movimento em direção às sociedades mais individualistas?

A questão exige um passo além das alternativas dualistas. Por um lado, deve-se salientar que a conversão minimalista demanda do fiel uma maior autonomia na elaboração das respostas diante das possibilidades presentes, retirando a autoridade seja do pastor ou clero no sentido amplo, seja da força moral da rede de fiéis de uma mesma congregação. Por outro lado, não se valoriza a subjetividade como elemento fundamental na tomada de decisão. Como pessoas que desposam uma crença, os conversos crêem na submissão da vontade pessoal a um desígnio transcendente maior, cuja manifestação é tanto subjetiva como concreta e material.

De uma perspectiva interna aos vários pentecostalismos, desconsiderar, por exemplo, a dinâmica dos eventos e da matéria seria uma das formas de negar o Criador, pois a exterioridade nada mais é que uma das manifestações de Sua presença diante dos homens. Isto quer dizer que mesmo que haja uma forte dose de voluntarismo nas dinâmicas pentecostais, ela é parte de uma perspectiva que inclui a existência de algo para além do sujeito, seja isto chamado realidade, evento, matéria ou mistério divino. Trago aqui um terceiro caso de conversão, em que a confirmação de uma profecia foi fundamental para a virada final em favor da nova adesão. Por seu intermédio poder-se-á ir além da identificação da postura pentecostal com relação às noções românticas de indivíduo e de liberdade pessoal (Corten et alii 1996).

\section{0 "instante" que se espera}

Antônia é angolana e negra. Em 1975 refugiou-se, junto com o marido português e os sete filhos, em Aldeia Nova, uma pequena aldeia no interior sul de Portugal. Com a independência de Angola, a situação do marido tornara-se insustentável dada a explosão de ódio e ressentimento diante da antiga metrópole, especialmente contra os cidadãos portugueses, representantes da elite colonizadora repudiada. Como os outros, Antônia e sua família perderam os bens acumulados por lá. Diante desta adversidade, tiveram um refúgio certo em Portugal, dentre outros motivos porque eles haviam construído uma casa na aldeia natal do marido, casa que tinha quatorze quartos para garantir o conforto da família e a boa hospitalidade.

Em função do casamento com um português, não houve dificuldade na legalização da permanência desse núcleo familiar em Portugal. Entre- 
tanto, a aliança matrimonial não regularizava a situação da mãe, do avô e da sobrinha, estes outros membros da família extensa que, por uma série de relações de favor e contrafavor tradicionais, foram incluídos no rol dos dependentes de Antônia. Sua conversão ao pentecostalismo está diretamente ligada à resolução desse problema.

Como Everaldo, Antônia guarda a lembrança de um momento específico, o instante da virada e da conversão final, que veio em continuidade ao processo mais demorado de familiarização da mensagem pentecostal. Conta, então, que estava no ano de 1990 ou 91, quando já havia tentado diferentes recursos para regularizar a situação desses três parentes. Várias viagens entre Aldeia Nova e Lisboa tinham sido feitas, em uma circulação sem fim entre os balcões do Ministério de Imigração e Fronteiras, onde Antônia juntava papéis e mais papéis no processo de legalização. Em uma determinada noite, ela retornou mais uma vez de Lisboa sem solucionar o problema, o que a deixou especialmente tensa e incomodada porque parecia que as últimas chances se tinham esgotado, já que dali a 24 horas se consumaria a expatriação dos seus. Foi aí que, lançando mão de uma prática corrente no meio pentecostal, Antônia propôs um desafio para o transcendente, que ela me narrou nos seguintes termos:

"Se este Jesus existe, como nós sabemos que ele existe, ele tem que me ajudar, tem que nos mostrar alguma coisa, tem que nos fazer algo. Nós só temos 24 horas, passando este dia os homens virão para levar minha mãe e os outros e colocá-los no avião. Nestas 24 horas, se Jesus não resolver o problema é porque ele não existe. Se ele existe (eu não tenho dinheiro prá ajudar na obra dele), mas se ele me ajudar, a partir de hoje ele vai me dar condições de ajudar. Quero que ele me dê orientação, uma resposta física mesmo, usando as pessoas aqui embaixo prá me dar uma resposta positiva. Se Jesus precisa de mim, se ele propriamente morreu na cruz por mim, ele tem que fazer alguma coisa agora por mim. E aí chorei, fartei-me de chorar."

Antônia conta que a resposta veio: na manhã seguinte ela recebeu uma carta enviada por uma alta funcionária do Ministério de Imigração e Fronteiras, convocando-a para uma reunião onde se anunciaria a regularização da situação dos seus. A extradição não ocorreu e Antônia teve sua resposta de fé, tornando-se, desde então, fiel dizimista da Igreja Universal do Reino de Deus.

Algumas linhas de boa antropologia já foram escritas para a desconstrução de perspectivas similares a esta do desafio de Antônia, formuladas a partir de uma visão circular do tempo, recorrentes em profe- 
cias, anúncios e adivinhações (Todorov 1992, por exemplo). Argumentase que dentre as possibilidades dadas em uma certa disposição dos eventos, o profeta, o místico ou o adivinho indicam o futuro, descrevendo uma alternativa dentre outras. Quando é justamente esta que se cumpre na cadeia dos eventos - que poderia a priori se cumprir, na medida em que se tratava de uma das possibilidades previamente dadas - o profeta ganha em carisma e autoridade aquilo que aparenta ser seu domínio sobre o sentido da história. Ao contrário, quando a profecia não se cumpre, geralmente cai no esquecimento. Isto porque, como afirma Todorov, a profecia salva aquilo que é central em uma sociedade tradicional, sua percepção preferencialmente circular do tempo: lê-se a cadeia de eventos como um ir e vir do conhecido e do sabido, no eterno retorno ao capital cultural acumulado pela sociedade.

Voltando ao nosso caso, é bastante plausível que Antônia tenha construído sua narrativa de trás para frente (maximizando uma tendência que está dada na formação de qualquer narrativa), de tal forma que, por exemplo, um pensamento despercebido anterior, como uma vaga idéia de ressentimento contra a impotência do transcendente, tenha, posteriormente, ganho uma outra dimensão. O sucesso da ação teria então transformado o que era residual na lembrança em um desafio dramático, pontuado, dialogal com o transcendente, bem ao estilo do pentecostalismo a que ela passou a aderir. Até aí não há problemas, dado que, a meu ver, uma das características mais evidentes do pentecostalismo atual é uma relação um tanto flexível com a linguagem, cuja melhor ilustração é a razoável banalização dos milagres e determinações, com a contínua correção de sentido ou de foco à medida que a cadeia dos eventos se desenrola ${ }^{13}$. Outra coisa é levar o ceticismo às últimas conseqüências, negando que tenha havido uma disposição mínima anterior sobre a qual se elaborou a releitura do passado.

É importante se fazer essa distinção porque, conforme uma ou outra interpretação, o sujeito que profetiza ganha posições completamente diferentes perante o dito. Na interpretação cética aceita-se a possibilidade de o profeta simplesmente manipular a lembrança do passado a partir do presente sem cobrar coerência e consistência da sua lembrança com a disposição anterior da cadeia de eventos. Aceita-se a idéia que um instante se forma sem estabelecer qualquer conexão com outro instante, onde a aleatoriedade é o componente principal da percepção no desenvolvimento da experiência ou no fluir da história. Na outra interpretação, o profeta experimenta a circularidade temporal internamente, apostando intuitivamente em um andamento específico da cadeia de eventos. Isto 
quer dizer que o profeta se engaja e arrisca - mesmo que minimamente ou com graus variados de compromisso - diante de um "tempo de espera". Ele visualiza o instante futuro, instante que corroborará o sentido das palavras proferidas. Trata-se do proferimento de palavras pouco banais, já que sem sua dimensão temporal elas se tornam completamente falhas.

Deslocando-se o foco de interpretação da intenção do sujeito para a dinâmica em curso, chega-se ao ponto mais rico do caso Antônia, ou seja, à especificidade da disposição pentecostal diante de eventos que são exteriores ao sujeito. Neste caso, com o desafio lançado ao transcendente, Antônia elaborou uma espera sobre um assunto que era do seu máximo interesse, mas sobre o qual não tinha domínio. A impotência da ação transformou-se em sobrepotência de sentido, pois justamente sua expectativa confirmou-se como o novo dado da realidade.

De forma geral, quando o crente se engaja em diferentes tempos de espera, aguardando respostas pontuais da cadeia de eventos, ele também fica comprometido com um processo de aprendizado sobre as regras de ordenação do mundo. Com os fracassos ele aprende seus limites, suas impossibilidades, os imponderáveis diante do acaso. Com o sucesso ele aprende que existe algo para além da escravidão diante do tempo.

Além disso, ao experimentar o presente como um momento dentro de um tempo de espera, o crente insere-se em uma temporalidade messiânica típica do cristianismo, pois o tempo de espera mundano e pontual justifica-se diante de uma espera maior, englobando toda a humanidade em uma expectativa - ainda que vaga e indeterminada - de que o transcendente se manifeste dando sentido à história. Complementarmente, que todo o movimento da história se desenvolva para confirmar Aquela divindade.

\section{A conversão minimalista}

Ao contrário da conversão máxima, que conta com o controle e coesão do grupo para encaminhar o converso para um "novo mundo de crenças e disposições", na conversão minimalista o indivíduo tem maior autonomia e responsabilidade para articular as crenças, a cosmologia e os mitos pentecostais com a sua trajetória anterior. Pluralizam-se assim as recriações religiosas a partir da nova adesão, aspecto que não deve ser confundido com alguma tendência de anulação de estabilizações e recorrências no interior das congregações religiosas, pois a valorização da recriação individual a partir da adesão à cosmologia pentecostal tem como continuidade, ora formações coletivas pouco institucionalizadas e fortemente atre- 
ladas a dinâmicas rituais (como a IURD), ora formações coletivas mais ligadas às dinâmicas e aos atores locais, dada a forte segmentaridade no interior do universo evangélico (Fernandes 1994).

Como procurei salientar, o que qualifica a conversão minimalista é a inclusão da trajetória individual em um "tempo de espera", quer dizer, a conversão demanda uma transformação existencial que não é sinônimo de fortalecimento da postura individualista. O tempo de espera está próximo à noção de projeto cunhada para descrever o processo de individualização na sociedade moderna, mas é distinto dela porque deve necessariamente estar mais aberto à intervenção do inesperado e do acaso (Velho 1994). Em termos distintivos, enquanto a melhor ilustração do projeto é a de uma carreira profissional, onde etapas gradualmente são somadas para a realização de um objetivo definível a priori, a melhor ilustração do tempo de espera é a do cultivo e desenvolvimento de uma relação humana, em que o objetivo final é necessariamente indefinível ainda que possa ser intensamente desejado e imaginado, pois o risco da degeneração e fracasso está sempre colocado. Ganha-se com isto maior organicidade na relação do sujeito com o mundo.

Também não entendo que essa postura seja exclusiva aos pentecostais. Pelo contrário, a noção tempo de espera foi cunhada por Lissovski (1997) a partir de uma reflexão sobre o desenvolvimento técnico-estético de um grupo de fotógrafos. Segundo a análise desse autor, fotógrafos tão distintos quanto August Sander, Henri Cartier-Bresson, Diane Arbus e Sebastião Salgado se encontram por experimentarem, cada um a seu tempo, cada um segundo um estilo singular, uma perspectiva para captar o "seu" instantâneo. O que os une, segundo o autor, não é o conteúdo da espera, mas essa disponibilidade para aguardar o instante em que uma determinada imagem pode ser capturada de dentro da cadeia de eventos. Quando aquela determinada imagem aparece, eles sabem que estiveram a esperá-la anteriormente e estão prontos para capturá-la.

As possibilidades de aproximação entre as duas análises são muitas, mas certamente existe uma diferença de fundo entre esses fotógrafos, que se entregam ao tempo de espera em nome do desenvolvimento de uma estética, e os pentecostais. A conversão pentecostal minimalista conta com pelo menos duas recorrências: a experiência do transe e a "Aceitação de Jesus Cristo". Por que estes dois aspectos são recorrentes?

Os ritos pentecostais estão pontuados de pequenas experimentações de transe — na oração forte, na expulsão dos demônios, na recepção do Espírito Santo, na glossolalia, no choro convulsivo diante de um Deus Grandioso. O transe ajuda a compor a nova disposição temporal na medi- 
da em que, no estado alterado de consciência, as percepções do contexto e da memória sofrem modificações. No transe pode-se experimentar a imobilidade ou mobilidade máxima, o vazio de lembranças ou a lembrança de tudo e todos ao mesmo tempo, a percepção de todos os sentidos ou a ilusão de sentido algum. Quer dizer, o transe abriga a experimentação de um outro tempo, o que dá o contraste mínimo mas necessário para se elaborar o instante do tempo de espera. Dito de outra forma, o transe ajuda a formular a passagem da conversão porque na sua outra temporalidade permite conceber gratuita, instantânea e plenamente o instante desejado a ser buscado no tempo de espera. Dessa forma, o transe pentecostal, ao contrário do transe afro-brasileiro, é conduzido e limitado no rito de modo a ser encaixado como um instrumento a mais em uma estratégia de conversão que pretende atingir a pessoa por inteiro, na sua autoconcepção e disposição diante do mundo ${ }^{14}$.

Se essa interpretação estiver certa, a experiência do transe pentecostal abre a pessoa para uma nova disposição. Contudo, a nova disposição é vaga e indeterminada e qualquer conteúdo, ideologia, narrativa etc. poderia, em tese, preenchê-la. Vale lembrar, então, a recorrência com que o nome de Jesus Cristo é citado junto com a experiência do transe, aspecto que deve ter sua importância. O que garante essa invariância? O que justifica essa recorrência de atribuição a uma imagem determinada, se em princípio a conversão abre não apenas para um símbolo mas também para uma ampla cosmologia pentecostal? Por que não há confusões e não ocorrem citações, por exemplo, do auxílio do Espírito Santo, esta figura da Trindade que simboliza o guia e o confortador mais próximo dos homens nas suas agruras? Onde se estabelece esse vínculo intrínseco entre a conversão pentecostal e a aceitação de Jesus Cristo?

Na cultura ocidental cristã Jesus Cristo ${ }^{15}$ é o símbolo máximo da piedade - ele se faz cordeiro por amor à humanidade que o recusa. Apropriando-se da complexa dialética desejante do mito, na "aceitação de Jesus Cristo" o crente realiza uma visada distanciada sobre sua própria trajetória a partir da perspectiva do estrangeiro (Deus-homem) que se sacrifica para o resgate de si (a humanidade). Com o auxílio do mito, o crente volta à região selvagem de si mesmo - pelo transe que o leva até a região não investida pela sua própria cultura - para retornar convencido da possibilidade da generosidade pura, ou melhor, do seu vínculo desejante com o devir do Dom pleno. Dessa forma, o crente pode se fazer despatriado de sua trajetória para retornar investido de uma vontade de reconstrução de si atento ao resguardo de suas idiossincrasias. Não haveria adequada afirmação de si sem a aceitação do estrangeiro em si. Nes- 
se sentido, a conversão minimalista desencadeia um trabalho de alargamento ontológico e não apenas de adesão a dados ou a pontos fixos e completos de uma cartilha institucional.

Como um outro instrumento cultural disponível nas sociedades em que o pentecostalismo se insere, a conversão minimalista não apenas abre mais uma possibilidade de reapropriação da cultura, mas realiza essa abertura em uma dada direção. Sem que se adira ao puro e simples elogio dos potenciais desse recurso cultural, pode-se afirmar que ela abre a possibilidade do desenvolvimento de ações mais livres, naquele sentido de liberdade cunhado por Bergson:

\footnotetext{
“Se há ações livres ou pelo menos parcialmente indeterminadas, elas só podem pertencer a seres capazes de fixar, em intervalos regulares de tempo, o devir sobre o qual seu próprio devir se aplica, capazes de solidificá-lo em momentos distintos, de condensar desse modo sua matéria e, assimilando-o, digeri-la em movimentos de reação que passarão através das malhas da necessidade" (Bergson 1990:173).
}

A liberdade bergsoniana, assim como a pentecostal, estabelece-se na consideração da tensão individualizada entre necessidade e vontade, percepção e memória, reposição e inovação. Daí a curiosa correlação entre as idéias de Bergson e a valorização no meio pentecostal da capacidade de atenção à vida do sujeito (sua capacidade de discernimento do momento em que se dá a junção entre expectativas e condições externas para que ocorra a ação pontual e eficiente do self), em vez de uma valorização da sua capacidade de intervenção (do sujeito como criador e inovador baseando-se em conceitos e projetos pessoais ${ }^{16}$.)

Como enfatizei ao longo do artigo, o abandono da noção de conversão maximalista em prol desta que estou chamando de minimalista, implica a diminuição do controle do grupo e da congregação sobre a autopercepção individual, que passa a levar mais em conta as nuanças e as sutilezas da experiência individual. Mas assim como a conversão minimalista abre caminho para uma maior diferenciação interna no bojo do pentecostalismo - ao levar em conta os relatos individualizados —, também promove a composição de narrativas cada vez mais similares umas às outras. Na última parte do artigo, sugiro algumas pistas para a compreensão desse processo relativamente homogeneizador, propondo que interpretemos o testemunho como um gênero narrativo.

Farei então um recuo que vem para compor um olhar mais alargado e distanciado da experiência testemunhal, construído a partir das refle- 
xões realizadas por Walter Benjamin no texto "O Narrador - Observa-

ções acerca da Obra de Nicolau Lescov" (1985) — este belo Réquiem ao conto como gênero narrativo. Nessa despedida, Benjamin discorre sobre os critérios que estabelecem as diferenças entre o conto e o romance, cada um deles analisado como expressões de momentos civilizacionais diferentes. A estes dois gêneros será agregado o testemunho, essa forma rotineira de relato da conversão entre os pentecostais, procurando entendê-lo na especificidade do contexto em que emerge, nesse caso, do bojo da sociedade contemporânea.

\section{Os testemunhos como um gênero narrativo}

É interessante a postura assumida por Benjamin nesse texto. Tal como o anjo apocalíptico, ele inicia sua análise falando do fim, do anúncio da destruição inevitável da narrativa tradicional e, conseqüentemente, da rarefação da troca de experiência vivida por meio de palavras. Para este prognóstico, ele leva em conta a Segunda Grande Guerra, a imprensa e sua massa de informações diárias, o encontro fortuito, veloz e inesperado das pessoas nas metrópoles, esses vários fenômenos que vêm transformar a matéria da experiência ou, nas suas palavras, fazer com que "as experiências percam muito de seu valor" (Benjamin 1985:63).

Por mais instigante e sagaz, podemos reler o prognóstico benjaminiano, com todo seu pessimismo civilizacional, como um dado de época. Essa última avaliação do fim do valor das experiências na sociedade moderna, por exemplo, nega a abertura e a indeterminação da história, quando se poderia admitir a possibilidade futura do surgimento de estilos narrativos centrados na experiência, ainda que de outra forma.

Ora, vários elementos levam a reconhecer no testemunho de conversão uma retomada dessa capacidade da troca pela palavra de experiências vividas (Benjamin 1985). Os testemunhos trazem para o primeiro plano a oralidade, envolvendo pessoas comuns relatando experiências pessoais de metamorfose nas suas vidas ${ }^{17}$. Nesse sentido, o testemunho multiplica o número de narradores, pois a qualificação demandada ao narrador é apenas a inclusão no conjunto, ou seja, sua participação na experiência da revelação. Como a matéria narrada é a experiência de revelação vivida, quem dá o testemunho não precisa dominar, como minimamente se requer de um contador de histórias, uma capacidade criativa mais afiada, um certo talento para transformar o corriqueiro em conselho. A simplicidade estrutural do testemunho e um certo minimalismo 
na sua composição — o antes e o depois da "aceitação de Jesus" — garantem a sua extrema adaptabilidade e possibilidade de multiplicação.

Por outro lado, o testemunho também resgata a experiência banal, cotidiana, de homens e mulheres comuns, matéria que parecia ter perdido valor em meio à intensidade da vida na sociedade moderna. Ao contrário do romance, que se desenvolve sem um propósito definido, o conto e o testemunho querem atingir o núcleo da vida ativa. A matéria do conto está, para Benjamin, na vida laboral das coletividades artesãs, geralmente arrancando do anonimato um conjunto de histórias comuns por um processo de tipificação e caricaturização. O herói do conto é fundamentalmente o homem prático perfeitamente ajustado à vida. Em Nicolau Lescov, este é especificamente reconhecido no homem justo, o qual é apresentado em um ou outro fragmento de vida dos diferentes personagens, uma vez que não se atualiza em ninguém integralmente. No testemunho, pelo contrário, a matéria narrada é o processo de metamorfose, expresso na fórmula de aceitar Jesus Cristo, invariavelmente vivido pelo autor. Não se trata, portanto, de um gênero narrativo referente ao desenrolar da vida de uma coletividade, mas de um outro individualizado, cujo objeto é a vida comum do autor que ganhou um colorido ou até mesmo uma nova aura pela experiência da metamorfose. Se o conto engrandece o herói que as comunidades guardam em si nos fragmentos da vida de seus membros, o testemunho engrandece o efeito de metamorfose, deslocando o foco do herói para o ato heróico que, a princípio, deve reunir todos aqueles que participam do gênero: "a aceitação de Jesus".

$\mathrm{O}$ ato heróico testemunhal envolve uma atenção redobrada às questões de sentido intrapessoais, um trabalho para descobrir o que ocorre em torno dos motivos, gostos e incentivos do sujeito em um dado contexto e situação, para que estes venham a se somar aos objetivos extrapessoais mais amplos. Envolve, portanto, uma luta contra a degeneração do ato em comportamento condicionado (puro habitus) ou experiência condicionada (resposta imediata às pressões da cadeia de eventos), cujo mérito maior será a atualização da revelação em tempo de espera.

É, portanto, estranha a função da revelação no testemunho (sempre anunciada e repetida), quase que simétrica e inversa à sua função no conto (única e surpreendente). O testemunho apresenta uma estrutura circular; a revelação é o princípio que inclui a narrativa no gênero testemunhal, a qual, por sua vez, deve desenvolver-se no sentido de salientar a eficácia daquela revelação na vida do autor. A revelação está ali como princípio e fim. No conto, pelo contrário, a revelação estabelece-se à medida que aparece junto com o elemento surpresa, no desenrolar inusi- 
tado de uma história que poderia assumir um outro desenvolvimento. Coloca-se, então, geralmente, no final, e quanto mais única e misteriosa em si mesma, menos irredutível ao desgaste pelo andar dos tempos.

Estabelece-se, assim, uma série de continuidades entre os dois gêneros - ambos exploram a oralidade, suas narrativas estão marcadas pela experiência do narrador e estabelecem no seio da vida prática a base do seu desenvolvimento. Mas essas continuidades são apenas superficiais: no conto, a autoria envolve um certo talento, um tratamento narrativo delicado, de tal forma que a revelação venha à tona na sua unicidade. A singularidade da narrativa não deve, entretanto, comprometer a simplicidade. Um conto é para ser contado e recontado coletivamente.

A revelação no testemunho é, como vimos, começo e fim - é através dela que as narrativas individuais são introduzidas no gênero, ocupando o corpo principal do texto. Essa circularidade e minimalismo estruturais permitem a multiplicação do gênero, que só pode realizar-se à medida que se amplia o número de autores - por definição, o testemunho é pessoal e intransferível. Nesse sentido, relatado por uma pessoa diante de platéias nos círculos das igrejas ou na mídia evangélica, ele está dirigido a uma platéia de potenciais autores. Em geral, o testemunho é contado para suscitar novos testemunhos. Diz respeito à vida de mulheres e homens comuns, uma maioria humilde e pouco instruída, formadora das massas na sociedade contemporânea ${ }^{18}$.

Além disso, o testemunho é um relato construído pelo indivíduo sobre sua experiência, sem entretanto ter por objetivo a valorização da singularidade daquela história. O romance é o inverso simétrico, pois busca capturar a peculiaridade: nele uma experiência individual é destacada do conjunto de todas as outras histórias humanas para revelar-se em sua solidão e idiossincrasia. O romance envolve um exercício explícito de relativismo entre as histórias pessoais, cada uma se estabelecendo em sua imponderável diferença. Destaca-se desse contraste entre testemunho e romance, o aspecto da comensurabilidade no núcleo das narrativas testemunhais. O gênero abarca todas as experiências de vida que se encontram na história de Cristo - um mito aberto para a inclusão de cada indivíduo, como vítima, como algoz, ou o híbrido entre as posições. A partir dessa inclusão, os crentes ganham a medida de sua semelhança nos relatos compartilhados. 
Clara Mafra é professora do Departamento de Ciências Socias da UERJ e doutora em Antropologia Social pelo PPGAS/MN/UFRJ. Entre outros artigos, publicou "Construção de Gênero e Estilo Eclesial entre os Evangélicos" (Revista da UFRRJ, 2/3, 1996), "Drogas e Símbolos: Redes de Solidariedade em Contextos de Violência" (In: A. Zaluar e M. Alvito, Um Século de Favela. Rio de Janeiro: Ed. FGV. 1998) e "Dialética da Perseguição" (Religião e Sociedade, 19(1), 1998).

\section{Notas}

1 O presente artigo é uma versão modificada do quarto capítulo da minha tese de doutorado Na Posse da Palavra - Religião, Conversão e Liberdade Pessoal em Dois Contextos Nacionais, defendida no PPGAS/MN/UFRJ em setembro de 1999. Como aqui enfoco basicamente o tema da conversão, remeto o leitor à tese para um exercício comparativo mais abrangente em termos etnográficos e de análise sociohistórica sobre as diversas expressões do pentecostalismo no Brasil e em Portugal.

2 Traços de um certo naturalismo encantado têm marcado o catolicismo popular português já de longa data (Sanchis 1979) e permanecem com vigor ainda hoje. Esta é uma das importantes indicações de recente pesquisa realizada por Machado Pais e equipe, segundo a qual cerca de 30\% dos católicos praticantes acreditam em espíritos, $25 \%$ dos praticantes e não praticantes em feitiçaria e $28 \%$ dos não praticantes, em astrologia (Pais 1998:493).

3 O movimento pentecostal teve início no Brasil com a chegada de missionários estrangeiros: um italiano, que fundou a Congregação Cristã do Brasil, em 1910, e dois suecos, que fundaram a Assembléia de Deus, em 1911. A partir daí, o pentecostalismo passou por diferentes etapas, fruto das acomodações entre diferentes ênfases missionárias e as condições sociopolíticas nacionais. Em uma classificação hoje tida como clássica, Paul Freston (1993) dividiu a história do movimento pentecostal em três: a primeira, no seu início, de 1910 até 1950, quando houve a ênfase nos dons de glossolalia e uma expansão marcadamente no Norte e Nordeste. Na segunda onda, entre 1950 e 1970, o movimento esteve marcado pelas tendas de evangelização de "cura divina", onde o dom de cura ganhou relevância e o pólo irradiador se transferiu para São Paulo. A partir de 1970, ocorre a terceira onda que, na sua origem, esteve mais concentrada no Rio de Janeiro, tendo como ênfase o dom da expulsão de demônios. Esta última onda, por acentuar uma dinâmica sincrética com outras religiosidades, além da de tradição evangélica, e por incorporar inúmeros traços de uma teologia da prosperidade, tem sido 
nomeada também como movimento neopentecostal. No artigo, tendo a usar o termo pentecostalismo no seu sentido amplo, englobando inclusive a terceira onda, guardando o termo neopentecostal quando a especificidade dessa corrente se faz evidente. Esta opção leva em conta que o fluxo de informações e influências no interior do campo evangélico é constante e intenso, de forma que as fronteiras entre as correntes sempre estejam se redefinindo e reassentando.

4 A pesquisa de campo foi realizada com os crentes moradores da favela Santa Marta, Botafogo, Zona Sul carioca, entre fevereiro e junho e setembro e dezembro de 1996. Em agosto de 1997, iniciei o campo em viagem a Portugal, acompanhando os freqüentadores da Igreja Universal do Reino de Deus em Lisboa, Coimbra e Porto. Nesta estada de seis meses no exterior, fui recebida como pesquisadora-visitante pelo Instituto de Ciências Sociais da Universidade de Lisboa e contei com uma bolsa da Capes, aos quais agradeço.

5 Todos os nomes citados no artigo são fictícios a pedido dos próprios entrevistados.

6 Estou fazendo uso um tanto livre do conceito de destradicionalização, entendendo-o como referência a processos sociais de distanciamento de heranças culturais exclusivistas ou simples abertura para sistemas simbólicos em competição em um dado contexto, sendo que o diferencial do processo é a perspectiva de uma postura menos naturalizada em relação aos sistemas simbólicos que servem de referência. Não suponho que todo processo de destradicionalização desemboque, necessariamente, em uma experiência mais individualista e instrumentalista da cultura, pois parece que, como argumenta Hellas, boa parte dos processos de destradicionalização vividos contemporaneamente tende a acelerar os processos de reinvenção das tradições ou a adesão a tradições alternativas. Uma obra de referência para a discussão é Detraditionalization, de Hellas, Lash e Morris (1996).

7 Otávio Velho tem chamado a atenção para os processos de desreificação e dissolução das oposições no interior dos novos movimentos religiosos, tais como o pentecostalismo e a Nova Era. No caso do pentecostalismo, o autor localiza na dinâmica de atribuição de significado ao "Espírito" a promoção de um movimento isomórfico, "atravessando as mais diversas sociedades e culturas como uma espécie de 'mal-entendido', produtivo na medida em que permita o prosseguimento de uma conversação" (Velho 1997:144).

8 Entre os Censos de 1981 e 1991, em Portugal, destacam-se dois movimentos percentuais complementares: um decréscimo da população que se identifica como católica (de 81,1\% para 77,9\%) e um aumento pequeno daqueles que se identificam com outras religiões (de 1,4\% para 1,8\%) (Vilaça 1997). Vale ressalvar, contudo, que o aumento mais significativo é o da população que preferiu não responder à questão sobre religião, que passou de 14,2\% para 17,6\% (INE, Recenseamentos Gerais da População 1981 e 1991). O Censo Brasileiro, que segue uma metodologia inversa, de criação da grade classificatória posterior à coleta de dados, registrou em 1991 apenas $0,4 \%$ de não respondentes, 83,0\% católicos, 8,6\% 
evangélicos (sendo 3,0\% evangélicos tradicionais e 5,6\% evangélicos pentecostais), 4,7\% sem religião, 1,1\% espíritas kardecistas, 0,4\% espíritas afro-brasileiros e 0,3\% de religião judaica (Censo Demográfico 1991 - IBGE). No Rio de Janeiro, a pesquisa Novo Nascimento (realizada em 1994) encontrou entre os evangélicos (12,0\% da população total - Censo 1991), 31,0\% de assembleianos, 19,0\% de batistas e $16,0 \%$ de universais.

9 Podemos remeter o dualismo vivido por Everaldo à tensão entre "a maximização da vida (através da totalidade da pessoa), que é um investimento no longo prazo e na duração, e a otimização do corpo (através da concentração no prazer), que é uma aposta no curto prazo e na intensidade", tensão presente no âmago da cultura ocidental moderna, segundo Duarte (1999:28).

${ }^{10}$ Não estou afirmando aqui que a conversão deva ocorrer de um modo ou de outro: por sedução ou coerção. Certamente, as conversões podem se dar segundo os mais diferentes caminhos, resultando, inclusive, nos mais diferentes níveis de adesão, tal como acontece com qualquer adesão individual a códigos culturais específicos disponíveis em meios sociais que admitem a pluralidade de opinião. Mas o imperativo ético do respeito ao direito ao livre-arbítrio é, tanto quanto eu tenho informações, um valor central entre os crentes nos mais diferentes países o que não significa que sempre seja cumprido.

11 Pesquisas empíricas como as de Maria Luiza Heilborn (1999) e Simone Monteiro (1999) indicam a generalidade do modelo de masculinidade apoiado na valorização da virilidade no contexto carioca, justamente o modelo que Everaldo pretende recusar a partir da conversão.

12 Para um aprofundamento do contrabando de categorias religiosas entre participantes de cultos afro-brasileiros e pentecostais, ver especialmente o artigo de Birman (1996).

${ }^{13} \mathrm{Na}$ minha tese (Mafra 1999) aprofundo essa questão da proliferação de milagres ou "causas impossíveis conquistadas" no interior da religiosidade pentecostal. A IURD é uma igreja privilegiada para se observar este fenômeno, tanto assim que recolhi nada menos do que 1.726 casos de relatos de milagres, publicados pelos jornais da Folha Universal (da IURD do Brasil) e da Tribuna Universal (IURD de Portugal), nas minhas pesquisas. Minha interpretação é que o rito pentecostal enfatiza o aspecto performático do rito. A Igreja Universal do Reino de Deus, por exemplo, orienta e admoesta constantemente os participantes dos seus ritos para que eles formulem com clareza e discernimento os resultados esperados na reunião. "Trabalhar o propósito" é uma categoria interna que diz respeito à elaboração dos freqüentadores sobre suas expectativas na participação do rito, organizando-a, em primeiro lugar, segundo uma divisão pelos dias da semana 2aa , cultos da busca da prosperidade; 3ạ, culto pela saúde; 4aa dos filhos de Deus; 5ạ, da família; 6aa, da libertação; domingo, do Espírito Santo. Os freqüentadores aprendem a definir os propósitos e as expectativas que os levaram a participar da dinâmica ritual, de tal forma que o fiel compartimentalize o tratamento de seus 
problemas, apresentando a Deus, por exemplo, a questão da busca do emprego do marido na 2a feira e a falta de harmonia do casal na 5a. Metaforicamente, o corpo de especialistas - os bispos e pastores da Igreja Universal - nunca tem o domínio completo do corpo de teses que será apresentado a cada sessão ritual, aspecto que não é problemático no desenvolvimento do rito. O bom andamento do rito pentecostal depende menos do acordo dos participantes diante de uma (ou várias) tradição(ões) e mais da sua performance, ou seja, que os muitos candidatos aprendam a nomear os seus problemas e a reconhecer que instrumentos culturais estão acessíveis para enfrentá-los, lutando dessa forma pelo milagre que perseguem e que a cosmologia pentecostal garante que virá.

14 Nesse sentido, concordo com as colocações de Marion Aubrée (1985) e Veronique Boyer (1996) quanto ao uso limitado por parte do pentecostalismo da experiência do transe incorporado da umbanda e do candomblé. Contudo, isto não nos leva a corroborar as críticas ao pentecostalismo em si, como se essa incorporação parcial reduzisse a riqueza do fenômeno social.

15 Etimologicamente, Jesus é a forma latinizada de um nome grego que, por sua vez, provém do hebraico (Jeshoschua ou Jeshua), significando ajudar, salvar. O título Cristo, que se transformou em nome próprio, provém de versão grega (Christos) de palavra também hebraica (Mashiah ou Messiah, o Messias, o ungido).

${ }^{16}$ Neste texto enfatizei a necessidade de compreender o fenômeno da conversão em sua singularidade e densidade significativa. As indagações acerca da questão da formação das continuidades e descontinuidades do processo pós-conversão levariam a outro desenvolvimento analítico, caso em que teríamos que enfocar o processo de normalização da vida pentecostal, as soluções para a reposição de certas fórmulas de verdade e as estratégias para a manutenção de uma certa tensão com o status quo.

${ }_{17}^{17}$ Susan Harding (1987) distingue, a partir da análise do testemunho de um pastor batista, várias das estratégias discursivas presentes no testemunho e que tendem a fazer do ouvinte um participante. A autora, além de fazer uma bela e sutil análise das nuanças de sentido presentes no discurso do pastor, expõe e engloba, enquanto tema de reflexão, o impacto do discurso na sua própria escuta.

18 Uma comparação entre os níveis de renda e a escolaridade da população evangélica e da população em geral na Região Metropolitana do Rio de Janeiro, realizada na pesquisa Novo Nascimento, confirma que "o perfil dos evangélicos diferencia-se pela concentração de pessoas menos escolarizadas e de menor renda" (Fernandes et alii 1998). 


\section{Referências bibliográficas}

AUBRÉE, Marion. 1985. “O Transe e a Resposta do Xangô e do Pentecostalismo". Ciência e Cultura, 37(7): 1070-1075.

BAILEY, Frederick George. 1971. Gifts and Poison: The Politics of Reputation. Oxford: Basil Blackwell.

BENJAMIN, Walter. 1985. "Sobre Alguns Temas em Baudelaire" e "O Narrador - Observações acerca da Obra de Nicolau Lescov". In: Os Pensadores. Rio de Janeiro: Ed. Abril.

BERGSON, Henri. 1990 [1939]. Matéria e Memória: Ensaio sobre a Relação do Corpo com o Espírito. São Paulo: Martins Fontes.

BIRMAN, Patrícia. 1996. "Cultos de Possessão e Pentecostalismo no Brasil: Passagens". Religião e Sociedade, 17(1-2):90-109.

BOYER, Veronique. 1996. "Possession et Exorcisme dans une Église Pentecôtiste au Brésil". Cahiers des Sciences Humaines, 32(2):243-264.

COLE, Sally. 1994. Mulheres da PraiaO Trabalho e a Vida numa Comunidade Costeira Portuguesa. Lisboa: Publicações Dom Quixote.

CORTEN, André et alii. 1996. Le Discours du Romantisme Théologique Latino-Américain. Montréal: Ciadest.

DUARTE, Luiz Fernando Dias. 1999. "O Império dos Sentidos: Sensibilidade, Sensualidade e Sexualidade na Cultura Ocidental Moderna". In: M. L. Heilborn (org.), Sexualidade: $O$ Olhar das Ciências Sociais. Rio de Janeiro: Zahar. pp. 21-30.

FERNANDES, Rubem Cesar. 1994. "Governo das Almas. As Denominações Evangélicas no Grande Rio". In: A. Antoniazzi et alii, Nem Anjos nem Demônios: Interpretações Sociológi- cas do Pentecostalismo. Petrópolis, R.J.: Vozes. et alii. 1998. Novo Nascimento: Os Evangélicos em Casa, na Igreja e na Política. Rio de Janeiro: Editora Mauad.

FRESTON, Paul. 1993. Protestantes e Política no Brasil: Da Constituinte ao Impeachment. Tese de Doutorado, Unicamp.

GREGORI, Maria Filomena. 1993. Cenas e Queixas: Um Estudo sobre Mulheres, Relações Violentas e Prática Feminista. São Paulo: Paz e Terra/Anpocs.

HARDING, Susan. 1987. "Convicted by the Holy Spirit: The Retoric of Fundamental Baptist Conversion". American Ethnologist, 14(1):167-180. HEILBORN, Maria Luiza. 1999. "Construção de Si, Gênero e Sexualidade". In: M. L. Heilborn (org.), Sexualidade: O Olhar das Ciências Sociais. Rio de Janeiro: Zahar. pp. 40-58. HEIRICH, Max. 1977. "Change of Heart: A Test of Some Widely Theories about Religious Conversion". American Journal of Sociology, 83(3):653680.

HELLAS, Paul, LASH, Scott e MORRIS, Paul (eds.). 1996. Detraditionalization. Cambridge: Blackwell Publishers.

LISSOVSKI, Maurício. 1997. O Refúgio do Tempo no Tempo do Instantâneo. Trabalho apresentado no VI Encontro Nacional dos Programas de PósGraduação em Comunicação. São Leopoldo, RS. Mimeo.

MAFRA, Clara Cristina. 1999. Na Posse da Palavra: Religião, Conversão e Liberdade Pessoal em Dois Contextos Nacionais. Tese de Doutorado 
em Antropologia Social, PPGAS/MN/ UFRJ.

MEYER, Brigit. 1994. "Beyond Syncretism: Translation and Diabolization in the Appropriation of Protestantism in Africa". In: C. Steward e R. Shaw (orgs.), Syncretism/AntiSyncretism. The Politics of Religious Synthesis. London: Routledge. pp. 45-68.

MONTEIRO, Simone. 1999. "Gênero, Sexualidade e Juventude numa Favela Carioca". In: M. L. Heilborn (org.), Sexualidade: O Olhar das Ciências Sociais. Rio de Janeiro: Zahar. pp. 117-145.

NOVAES, Regina Reyes. 1985. Os Escolhidos de Deus. Rio de Janeiro: ISER. OVERING, Joanna. 1989. "There Is No End of Evil: The Guilty Innocentes and their Fallible God". In: D. Parking (org.), The Anthropology of Evil. London: Basil Blackwell. pp. 244278.

PAIS, José Machado (org.). 1998. Gerações e Valores na Sociedade Portuguesa Contemporânea. Lisboa: Instituto de Ciências Sociais de Lisboa. PINA-CABRAL, João. 1989. Filhos de Adão, Filhas de Eva: A Visão de Mundo Camponesa no Alto Minho. Lisboa: Publicações Dom Quixote.

SANCHIS, Pierre. 1979. "Festa e Religião Popular: As Romarias de Portugal". Revista de Cultura Vozes, LXXIII(4):5-18. .1994. "Prá Não Dizer que Não Falei de Sincretismo". ComunicaÇões ISER, 13(45).

SOARES, Bárbara M. 1999. Mulheres Invisíveis: Violência Conjugal e Novas Políticas de Segurança. Rio de Janeiro: Civilização Brasileira.
TODOROV, Tzvetan. 1992. The Conquest of America. New York: Harper Perennial.

VILAÇA, Helena. 1997. "Notas de Pesquisa para o Estudo dos Grupos Religiosos Minoritários em Portugal". Revista da Faculdade de Letras, série I, VII:31-51.

VELHO, Gilberto. 1994. Projeto e Metamorfose. Antropologia das Sociedades Complexas. Rio de Janeiro: Zahar.

VELHO, Otávio. 1997. “Globalização: Antropologia e Religião". Mana, 3(1):133-154. 


\section{Resumo}

Duas tendências têm caracterizado a interpretação dos relatos pentecostais de conversão. Por um lado, um construtivismo forte, no qual a narrativa do crente é vista como resposta plástica ao jogo de expectativas e pressões externas. Na tendência inversa, a narrativa da conversão ocupa o centro da análise, e é interpretada como a expressão direta de uma nova disposição do self. Neste artigo, a partir de relatos de conversão de evangélicos brasileiros e portugueses, sugere-se uma terceira via de interpretação, na qual a conversão é tomada como gênero narrativo que abarca as experiências de vida do homem e da mulher comuns, os quais se encontram na "aceitação de Jesus Cristo", ganhando a partir desse evento, a medida de sua semelhança. Garante-se, assim, a comensurabilidade entre diferentes histórias de vida sem a imposição de uma unidade de sentido.

\section{Abstract}

Two broad trends have characterized the interpretation of documents which report on Pentecostal conversion. On the one hand, a "constructivist" tendency is observed, where the subject's narrative is seen as an artificial response or reflex to the forces of expectations and external pressure. On the other hand, narratives on conversion are treated as being the centre of analysis, and interpreted as the direct expression of some new disposition of the self. In this article a third interpretation is put forth, based on conversion reports from Brazil and Portuguese "Evangelicists", in which conversion is itself treated as a narrative genre which incorporates the life experiences of common men and women who have come to "accept Jesus Christ", and which gain, through this event, a measure of similitude. In this way one guarantees the commensurability of life his stories without imposing a single meaning upon them. 